\title{
APRENDIZAGEM DA PRONÚNCIA DE LÍNGUA INGLESA POR FALANTES DO PORTUGUÊS BRASILEIRO: ORALIDADE E ARTICULAÇÃO DO -ED DO SIMPLE PAST
}

\author{
LEARNING OF THE ENGLISH PRONUNCIATION BY \\ SPEAKERS FROM BRAZILIAN PORTUGUESE: ORALITY AND \\ ARTICULATION OF-ED FROM SIMPLE PAST
}

\author{
Rafael Alves de CASTILHO' \\ Marta Aparecida Oliveira Balbino dos REIS²
}

\begin{abstract}
Resumo: Este trabalho tem como objetivo examinar a pronúncia de verbos regulares da língua inglesa conjugados no simple past na produção oral de estudantes brasileiros de um Centro de Estudos de Línguas - CEL da cidade de Assis-SP. O foco do estudo desta pesquisa é a pronúncia dos três alomorfes: /t/, /d/ e /id/ no tempo verbal supracitado. Após o levantamento bibliográfico de cunho teórico prático (BLAND, 1996; LAFACE; TASHIRO, 2006; UR, 2012), e a coleta de dados, realizada por meio das gravações de produções orais dos alunos, foi possível analisar as variantes fonéticas e as interferências ocorridas. Durante essa análise, foram consideradas a proposta didático-pedagógica do Estado no que se refere aos cursos de língua inglesa oferecidos nos CELs, a duração desses cursos e o material didático utilizado, fornecido pelo Estado. Pudemos constatar a importância e a necessidade, tanto para os alunos quanto para os professores, de dar maior ênfase em questões e atividades que tratem da produção oral e da pronúncia da língua inglesa.
\end{abstract}

Palavras-chaves: Pronúncia. Fonética. Fonologia. Língua inglesa. Simple past.
Abstract: This work aims to examine the pronunciation of English regular verbs conjugated in the Simple past produced by Brazilian students from Centro de Estudos de Línguas - CEL from AssisSP. The focus of this study is the pronunciation of the three allomorphs: /t/, /d/ and /id/ variations of $e d$ in the verb tense mentioned. After the literature review (BLAND, 1996; LAFACE; TASHIRO, 2006; UR, 2012), data collection, done through recordings of students' oral productions, it was possible to analyze the phonetic variants and the occurred interferences. During this analysis, we considered the didacticpedagogical proposal of the State about the English language courses offered in the CEL, the duration of these courses, and the didactic material used, provided by the State. We could see the importance and the need, both for students and teachers, of a greater emphasis on questions and activities dealing with oral production and pronunciation of the English language.

Keywords: Pronunciation. Phonetics. Phonology. English language. Simple past. 1 Universidade Estadual de Londrina (UEL), Londrina, Paraná, Brasil; rafael.cast@hotmail.com;
https://orcid.org/0000-0002-6729-7043

2 Universidade Estadual de Londrina (UEL), Londrina, Paraná, Brasil; martatim85@yahoo.com.br; https://orcid.org/0000-0002-2391-138X 
- Aprendizagem da pronúncia de língua inglesa por falantes do português brasileiro: oralidade e articulação do -ed do simple past

\section{Introdução}

O interesse pelo ensino comunicativo de línguas estrangeiras (LE), conforme Mar (2006), tem se tornado um assunto bastante explorado no que concerne à sala de aula como ambiente em que o ensino formal de língua estrangeira é processado, sobretudo, para um quadro de estudos que considera primordial o desenvolvimento da proficiência do professor, na esperança de que o ensino e a aprendizagem de LE sejam um processo eficiente de aprendizagem.

Neste caso, é necessário que o professor esteja consciente das mudanças ocorridas nos últimos tempos sobre como ele ensinará, e como os alunos aprenderão a LE e, ainda, que se preocupe com a construção de todo esse processo, portando como profissional reflexivo, analisando sua postura pedagógica e posicionando-se como um intelectual crítico.

Conforme Rosa e Mar (2006), o professor é quem conduz o desenvolvimento das aulas. No entanto, podemos notar que a concepção de que o professor é o único detentor de conhecimento tem mudado; o aluno também é detentor de conhecimento e responsável pela condução das aulas, embora seja o professor quem cria, recria e desenvolve atividades que possibilitam o desenvolvimento das habilidades de seus alunos e que dá conta de suprir as deficiências e lhes permitir avançar nas conquistas. $\mathrm{O}$ envolvimento deles é que guiará o planejamento das aulas. É importante que o professor observe e analise as dificuldades e barreiras que impedem o desenvolvimento da aprendizagem da Língua Inglesa (LI) apresentadas pelos alunos e, também, os elementos positivos que contribuem para evolução do processo comunicativo nesta língua.

Sánchez Pérez (1997, p. 134 apud MAR, 2006, p. 181) afirma que: “[...] devese destacar que a necessidade de aprendizagem de línguas de maneira prática surge à medida que as línguas modernas começam a integrar-se nos currículos escolares de maneira obrigatória [...]", ou seja, o professor deve procurar atender a necessidade de adequação das práticas de ensino aos anseios de cada tempo.

Dessa forma, esta pesquisa trata de um estudo que aplica conhecimentos linguísticos ${ }^{3}$, auxiliando no resgate de uma abordagem dos aspectos fonéticos e fonológicos em sala de aula. Estudos acadêmicos têm se ocupado dessa temática no

\footnotetext{
3 Entendemos por conhecimentos linguísticos as categorias de análise da estrutura da língua (fonética, fonologia, morfologia, sintaxe e semântica).
} 
âmbito da $\mathrm{LI}$, mas sempre a partir de uma análise de processos morfofonológicos ${ }^{4} \mathrm{ou}$ voltada à análise de material didático, por exemplo: se o material traz ou não e como traz exercícios voltados à pronúncia.

Temos por objetivo discutir as formas variantes de pronúncia realizadas por aprendizes brasileiros de LI que mais comumente se desviam da norma padrão ${ }^{5}$. Pretendemos ilustrar como isso ocorre dentro da sala de aula e, para nossa análise, escolhemos o CEL da cidade de Assis e seus alunos. Apresentamos dados obtidos ao longo da observação de 2 encontros (4 aulas), e suas análises, comparando as duas línguas, o inglês e o português, buscando entender por que tais variantes fonéticas ocorrem e, por meio da conscientização dos alunos, intervir com o objetivo de evitar tais desvios.

Em um primeiro momento, consideramos relevante refletir sobre o ensino de língua inglesa como língua estrangeira e frisar a importância do trabalho da pronúncia dentro da oralidade. Em seguida, tratamos de aspectos teóricos de fonética e fonologia que servirão de base à observação, sistematização e descrição dos dados coletados durante o processo.

Num segundo momento, retomamos o processo morfofonológico de formação do simple past na fala do inglês padrão, passando à apresentação da metodologia e dos recursos do trabalho, da descrição e contextualização do objeto de análise (CEL e informantes).

Por fim, apresentamos a parte prática do estudo, detalhando cada etapa desenvolvida, descrevendo e analisando os dados obtidos por meio delas.

\section{Ensino de inglês como língua estrangeira}

Podemos inferir que a concepção que se tinha em relação à abordagem tradicional do ensino de LE é que ela defendia a ênfase nos aspectos gramaticais e no vocabulário, muitas vezes abordados sem referência à situação de comunicação. Assim, o professor ditava as regras que deveriam ser seguidas pelos alunos para que falassem uma língua estrangeira adequadamente. Portanto, aprender uma língua era conhecer sua estrutura e vocabulário, ou seja, sua morfologia, sintaxe e léxico. Com isso, surgiu a concepção equivocada de que língua e gramática eram as mesmas coisas.

\footnotetext{
4 Segundo Gomes (2009), processos morfofonológicos estão ligados às restrições fonotáticas da língua materna. Em outras palavras, as dificuldades encontradas na produção do morfema podem surgir do ambiente fonológico encontrado quando o -ed se junta ao radical.

5 Tomamos como pronúncias padrão para -ed as formas descritas no Oxford Advanced Learner's Dictionary (2010) por ser este um dicionário renomado, completo e atualizado.
} 
- Aprendizagem da pronúncia de língua inglesa por falantes do português brasileiro: oralidade e articulação do -ed do simple past

No entanto, podemos perceber que essa concepção ainda não foi de todo superada. Devido às inúmeras problemáticas em torno de um ensino comunicativo de LE, voltado a situações reais e práticas no ensino público, o trabalho com a produção e compreensão oral é dificultoso, pois, de acordo com o material didático disponibilizado pelo governo, o foco se dá na compreensão e produção textual, passando pelas estruturas gramaticais.

Fatores como o grande número de alunos em uma mesma turma, poucas horas/ aulas dedicadas ao ensino de LE, escassez de recursos tecnológicos e materiais autênticos em LE condicionam o professor a elaborar gramáticas pedagógicas, dicionários bilíngues e frases desconectadas de situações de comunicação.

Ao consultarmos a Base Nacional Comum Curricular, observamos o intuito de se construir uma educação voltada ao desenvolvimento do engajamento e da participação do aluno em um mundo social, contemplando não só habilidade escrita e leitora, mas também a oralidade (compreensão e produção oral), componentes linguísticos e dimensão intercultural.

Aprender a língua inglesa propicia a criação de novas formas de engajamento e participação dos alunos em um mundo social cada vez mais globalizado e plural, em que as fronteiras entre países e interesses pessoais, locais, regionais, nacionais e transnacionais estão cada vez mais difusas e contraditórias. (BRASIL, 2018, p. 241).

A importância dada pelo estado de São Paulo ao ensino de LE, sobretudo à LI, justifica-se por possibilitar ao aluno inserir-se no mundo globalizado, um processo de inclusão ao exercício pleno de sua cidadania. Nesse sentido, o fato de a LI estar presente na grade curricular das escolas públicas e privadas contribui para fazer com que o aluno compreenda a posição que ocupa dentro desse mundo globalizado, quais os motivos que o levaram a estar neste lugar e como ele se sente diante de determinada situação em que deva utilizar a língua.

No entanto, ao analisarmos alguns dos materiais didáticos usados em sala de aula e distribuídos pelo governo do estado de São Paulo ${ }^{6}$, deparamo-nos com a escassez de exercícios e proposição de situações pedagógicas que estimulem a inserção do aluno em situações reais de comunicação em LE. A ênfase na estruturação da frase e uso do

6 Materiais didáticos considerados são "Caderno do Aluno", para o ensino regular, e "Apostila de Inglês", para o Centro de Estudos de Línguas, dividida em 3 volumes. 
vocabulário, colocados em primeiro plano, e o uso de situações reais de comunicação apenas como pano de fundo para ilustrar questões gramaticais denunciam uma precarização da comunicação oral.

Sendo assim, podemos perceber por meio de estágios de observação e experiências em salas de aula que a possibilidade de produção comunicativa por parte dos alunos é, algumas vezes, estimulada não pelo material didático, mas por iniciativa do professor. $\mathrm{O}$ docente é o sujeito que cria situações de fala em que o aluno possa exercitar, entre outras coisas, a pronúncia, combinando os sons da língua, observando e aperfeiçoando seu uso numa comunicação eficaz.

\section{Fonologia aplicada ao ensino de inglês como língua estrangeira}

\section{A fonética e a fonologia no sistema linguístico}

A fim de delinear os componentes teóricos basilares no que concerne à Fonética e à Fonologia, cumpre dizer, primeiramente, que a Fonologia é o ramo da Linguística que se ocupa dos fonemas. A Fonética, por sua vez, vincula-se ao estudo dos sons, de modo genérico. Para Saussure (2012), em seu Curso de Linguística Geral, a Fonética é uma ciência histórica, que analisa acontecimentos, transformações e que se move no tempo. Por sua vez, a Fonologia se impõe fora do tempo, pois o mecanismo da articulação permanece estável de acordo com a estrutura da língua em questão. Ainda que não seja uma concepção contemporânea, Saussure foi o primeiro linguista a fazer a separação entre as duas ciências, através do uso de suas dicotomias (Langue/Parole, Forma/Substância). Assim, foi com os integrantes do Círculo Linguístico de Praga que a Fonética e a Fonologia assumiram seu próprio objeto de estudo. A breve teoria que ora se apresenta encontrase baseada na obra Iniciação à Fonética e à Fonologia (1995), de autoria de Dinah Callou e Yonne Leite, grandes autoridades no assunto, em nosso país. Callou e Leite (1995) teorizam e estudam o inventário dos sons de uma língua de acordo com diferenças articulatórias perceptíveis; por exemplo, quando se distingue entre o "b" de "bobo" e o "b" de "bombo".

A Fonologia, por outro lado, estuda os elementos fônicos, ou unidades da língua sob o viés de sua função. Em Português, sabemos que há uma unidade / p / "pata", porque se mudarmos para / I/, temos outra palavra - "lata". De modo análogo, o vocábulo "peso" se mudarmos para / t /, "teso"; e, se substituirmos por / I /, "leso", etc. Neste caso, as unidades $/ \mathrm{p} /, / \mathrm{I} / \mathrm{l} / \mathrm{t} /$, que estão atuando no nível da linguagem, ou que são a forma da expressão, são chamadas de fonemas. 
- Aprendizagem da pronúncia de língua inglesa por falantes do português brasileiro: oralidade e articulação do -ed do simple past

Os fonemas, portanto, são as menores unidades fonológicas em que um conjunto fônico pode ser dividido, sendo sua principal característica a capacidade de diferenciar significados.

É fundamental perceber que a articulação dos fonemas é produzida pela liberação de ar dos pulmões por expiração. O ar vai para os brônquios, a traqueia e depois a laringe, onde estão as cordas vocais.

Se as cordas vocais se aproximarem e vibrarem, o som articulado é sonoro, mas se, pelo contrário, não vibrarem, o som fica surdo. Uma maneira muito simples de saber se um som é surdo ou sonoro é emiti-lo em voz alta e verificar, colocando a mão sobre a garganta, se vibrações se produzem; se sim, o som é sonoro. Caso contrário, será surdo.

No que tange aos sons sonoros, distingue-se entre os fonemas vocálicos e os consonantais. Os fonemas vocálicos são pronunciados de tal maneira que o ar não encontra nenhum obstáculo e, também, são capazes de formar sílabas por si mesmos. Dependendo da localização ou da parte da boca em que ocorre a sua articulação, as vogais podem ser anteriores, centrais e posteriores. Dependendo do grau de abertura da cavidade oral quando pronunciada, as vogais podem ser de três tipos: abertas, fechadas e médias.

Consoantes são fonemas que resultam da passagem do ar que sai dos pulmões pela boca/nariz, encontrando obstáculos para serem pronunciados. Consoantes são fonemas (sons) que encontram obstáculos durante a passagem pelo aparelho fonador. Podemos classificá-los do seguinte modo:

Oclusivos: são caracterizados por bloquear o fluxo de ar. Por exemplo: / p /, / t/, $/ \mathrm{k} /, / \mathrm{b} /, / \mathrm{d} /, / \mathrm{g} /$.

Fricativos: caracterizam-se por certa dificuldade para a expulsão do ar, mas sem impedi-lo. Seguem alguns exemplos: / f/,/s /.

Nasais: são fonemas, em cuja articulação, o ar é expelido ao mesmo tempo pela boca e pelo nariz.

Laterais: nestes, a língua está localizada no centro superior da cavidade oral, fazendo com que o ar escape de seus lados. Por exemplo: / / , / r /.

Vibrantes: há, neles, uma repetição muito rápida de sucessivos contatos ou vibrações da ponta da língua nos alvéolos. 
De acordo com o local de articulação, os fonemas podem ser classificados em: labiais (aqueles cuja articulação os lábios intervêm principalmente), dentais (aqueles em que os sons articulados tocam a ponta dos dentes na língua), alveolares (aqueles que se articulam aproximando a ponta da língua aos alvéolos), palatais (aqueles articulados trazendo a língua para mais perto do palato), e velares (aqueles que se articulam aproximando a língua ao véu palatino, ou tocando-o).

Isto posto, pode-se afirmar, de acordo com Callou e Leite (1995), que para qualquer estudo de natureza fonológica, é fundamental partir do conteúdo fonético, articulatório e/ou acústico, a fim de determinar as unidades distintivas de cada língua. Portanto, a Fonética e a Fonologia não são dicotômicas, uma vez que a Fonética trata da substância da expressão, ao passo que a Fonologia ocupa-se da forma da expressão.

\section{A pronúncia no processo de ensino e aprendizagem da LI: articulação, ritmo, entonação e intensidade}

Entende-se por pronúncia o conjunto de características fonéticas articulatórias e acústicas mobilizadas pelo falante em determinada língua. Espera-se que os fonemas realizados pelo falante, bem como o ritmo de sua fala e o percurso melódico (tonal) da fala, estejam enquadrados aos modelos de uma determinada comunidade de fala.

Conforme Ur (2012), não há a necessidade de que um aluno de LI modele sua pronúncia exatamente como a de um falante nativo, pois a comunicação pode se dar apesar dos diferentes sotaques. De fato, a expressão oral de um país que fala inglês como língua nativa pode ser de difícil compreensão para um falante não nativo. Nesse caso, é necessário investir em um curso de conversação, ou em aulas e atividades voltadas à oralidade, mais precisamente ao aperfeiçoamento da pronúncia, caso o estudante tenha interesse em aprimorar esse aspecto linguístico para garantir a inteligibilidade.

De acordo com Jenkins (2002 apud UR, 2012, p. 128, tradução nossa7), "alguns erros de pronúncia em conversações em inglês internacional podem, na verdade, provocar falhas de comunicação". Por exemplo, a substituição de um som curto /I/ por um longo /i:/em uma palavra como o verbo live, a faz soar como como leave, gerando uma confusão em nível lexical, caso seja utilizada de forma descontextualizada. Portanto, é necessário que os professores de LI percebam se os alunos estão sabendo diferenciar esses dois sons e utilizá-los corretamente.

7 No original: "Some mispronunciations in international English conversations can actually bring about breakdown in communication.". 
- Aprendizagem da pronúncia de língua inglesa por falantes do português brasileiro: oralidade e articulação do -ed do simple past

Segundo Ur (2012), o ritmo do discurso de um falante nativo de inglês caracterizase como ritmo-acentual. Isso significa que, em cada frase, certas palavras são prolongadas (geralmente, as palavras lexicais que carregam o conteúdo principal) enquanto outras são encurtadas para se adequarem ao ritmo. Então, o tempo que cada frase leva para ser dita depende de quantas tônicas há nela. Por exemplo: My old GRANDmother used to go RUNning in the middle of NoVEMber não demora muito mais para ser dita do que My GRANDma went RUNning in NoVEMber porque, embora a segunda frase possua um menor número de sílabas em relação à primeira, possui a mesma quantia de tônicas.

Já outras línguas caracterizam-se por possuir ritmo silábico: o tempo que leva para a frase ser dita depende de quantas sílabas possui. Portanto, a primeira frase acima, se pronunciada de acordo com o ritmo silábico, com 18 sílabas, levaria muito mais tempo para ser dita do que a segunda frase, com 10 sílabas.

Entretanto, muitas pessoas atualmente falam inglês com sílaba acentual mais do que com ritmo acentual, ou usam uma mistura dessas formas, todas aceitas mundialmente, e por isso pode não ser vantajoso investir muito esforço em treinar alunos a produzirem discurso ritmo-acentual. Eles, entretanto, precisam estar hábeis para ouvir e compreender ambos os tipos. Portanto, se faz necessário expô-los a uma variedade de diferentes ritmos em atividades de compreensão oral.

Acento tônico denota, na Linguística, a tonicidade, ou seja, a elevação tonal de determinadas sílabas das palavras durante a fala. Sílabas acentuadas parecem ser pronunciadas com mais força do que as que não são. À variação de altura das vogais na fala dá-se o nome de entonação. Além do ritmo, determinado pela duração das sílabas, é por meio da entonação que se produz a ênfase na fala, caracterizando-se assim a prosódia. Esses elementos são estudados pela fonética acústica e são de grande importância para a atuação do falante ao enunciar.

Falantes de inglês sinalizam quais palavras pronunciam mais forte em uma frase não pelo aumento da intensidade, mas normalmente pela elevação da entonação. Portanto, a mensagem transmitida pela frase John came by car this afternoon variará de acordo com qual palavra é pronunciada em um tom mais alto do que as outras. Por exemplo: se disserem: JOHN came by car this afternoon, enfatiza-se que foi a John que veio e não outra pessoa; John came by CAR this afternoon enfatiza que John veio de carro e não de moto; John came by car this AFTERNOON destaca que foi à tarde que Ele veio e não à noite.

O uso incorreto da entonação pode acarretar desentendimentos. Neste caso, se faz útil fazer com que os estudantes estejam cientes sobre como expressar uma tônica em uma frase e fazê-los praticar isso. Para que possamos passar à execução experimental 
dessa prática de ensino, precisamos, antes, fazer um apanhado das características de pronúncia do tempo verbal que escolhemos para a experiência: o simple past.

\section{Metodologia de pesquisa e informantes}

\section{Metodologia de pesquisa}

Para o desenvolvimento desta pesquisa, os procedimentos metodológicos foram divididos em quatro etapas.

A primeira etapa constituiu-se da observação de quatro aulas de LI em uma turma do Centro de Estudos de Línguas (CEL) da cidade de Assis-SP.

A segunda etapa contou com a gravação do áudio da pronúncia dos informantes. Os alunos/informantes receberam uma lista elaborada de verbos regulares em inglês para que pudessem pronunciar e serem gravados por meio de um gravador de modo que permitisse constatar se há dificuldades de pronúncia do sufixo -ed do inglês.

A terceira etapa proporcionou não só aos alunos selecionados, mas a todos os alunos da sala, uma intervenção ${ }^{8}$, com o objetivo de melhorar suas pronúncias deste tempo verbal.

$\mathrm{Na}$ quarta etapa, os alunos selecionados tiveram tempo para estudar e, com a mesma lista de verbos utilizada na segunda etapa, eles deveriam pronunciá-los novamente para que, finalmente, fosse possível analisar, confrontar esses dados com os da segunda etapa e concluir se a intervenção atuou como facilitadora no processo de ensino e aprendizagem.

\section{O Centro de Estudos de Línguas (CEL)}

O Centro de Estudos de Línguas é um projeto do governo do estado de São Paulo que tem como objetivo oferecer ensino de LE para alunos da rede pública. As línguas oferecidas são: inglês, espanhol, francês, italiano, alemão, japonês e mandarim.

Atualmente, são mais de 200 unidades espalhadas por todo o estado de São Paulo e as línguas ofertadas em cada unidade dependem da demanda dos alunos. Com exceção do curso de língua inglesa, os das demais línguas (espanhol, francês, italiano, alemão, japonês e mandarim) têm duração de 6 semestres, ou seja, 3 anos. Cada semestre equivale

8 Explicada na terceira etapa do item 5 - Análise dos dados. 
- Aprendizagem da pronúncia de língua inglesa por falantes do português brasileiro: oralidade e articulação do -ed do simple past

a um estágio e o curso é divido em níveis I e II: $1^{\circ}$ semestre: $1 \mathrm{~A} / \mathrm{I}, 2^{\circ}$ semestre: $2 \mathrm{~A} / \mathrm{I}$, $3^{\circ}$ semestre: $3 \mathrm{~A} / \mathrm{I} \mathrm{e} 4^{\circ}$ semestre: $1 \mathrm{~A} / \mathrm{II}, 5^{\circ}$ semestre: $2 \mathrm{~A} / \mathrm{II}$ e $6^{\circ}$ semestre: $3 \mathrm{~A} / \mathrm{II}$.

Devido ao fato de a LI já ser ofertada no currículo do ensino regular, seu curso tem duração de apenas um ano e não é dividido por semestre como os das outras línguas. Ele é anual.

Podem cursar as línguas ofertadas pelo CEL alunos que estão no ensino fundamental II (a partir do $7^{\circ}$ ano), ensino médio e EJA, devendo estar devidamente matriculados na rede pública. Para a língua inglesa, é necessário que o aluno esteja obrigatoriamente no ensino médio.

\section{Sujeitos da pesquisa/informantes}

Do total de 20 alunos, apenas dois foram selecionados. Os informantes foram alunos do CEL, sendo um do primeiro ano e o outro do segundo ano do Ensino Médio. Ambos apresentam nível de conhecimento básico na língua inglesa e a estudam desde o $6^{\circ}$ ano do ensino fundamental. Um dos informantes é do sexo masculino e o outro do sexo feminino, com idade entre 16 e 17 anos.

B.S.L, feminino, 16 anos, frequentou escolas públicas e seu contato com a língua inglesa, antes de ingressar no CEL, sempre foi no ensino regular. Ela será identificada no trabalho como Fernanda.

P.T.M.R, masculino, 17 anos, frequentou escolas públicas. Nunca estudou língua em escola privada de idiomas e seu contato com a língua inglesa começou no ensino regular. Ele será denominado no trabalho como Antônio.

Os informantes foram convidados a participar do processo por meio de carta entregue em mãos para a coordenadora do Centro de Estudos de Línguas pelo pesquisador para a coleta de dados e assinaram autorização escrita.

\section{Análise dos dados}

\section{Primeira etapa}

A primeira etapa da coleta de dados se deu pela observação em sala de aula. $\mathrm{Na}$ apresentação do simple past planejada pela professora da turma, o objetivo foi analisar a recepção e o desenvolvimento dos alunos em relação a este tempo verbal, sobretudo observando as primeiras pronúncias dos verbos regulares no passado, de modo que 
a intervenção pudesse ser elaborada e aplicada na terceira etapa. De acordo com o planejamento da professora, seriam necessárias 4 aulas (2 na terça-feira e 2 na quinta-feira) para o ensino do simple past da língua inglesa. A primeira etapa foi necessária para que os alunos/informantes fossem selecionados (de forma aleatória) e para que fosse possível desenvolver-se a segunda etapa.

Dentre várias atividades de listening (compreensão oral) e speaking (produção oral) elaboradas pela professora, apenas por meio de uma atividade de speaking (produção oral) foi possível detectar a forma como os alunos pronunciavam alguns verbos regulares do inglês no simple past, pois foi a que deu margem para que eles oralizassem tais verbos.

É válido ressaltar que as aulas observadas nesta etapa foram planejadas coincidentemente como pós recesso de aulas do mês de julho. Desta forma, permitiu que a professora pudesse iniciar sua aula com a pergunta "How was your vacation?" e entrar no assunto simple past. No entanto, se as aulas fossem dadas em outra época do ano, a professora poderia abordar o mesmo assunto de outra forma, como por exemplo: "How was your weekend?" ou "How was your day?"

Dentre as explicações gramaticais, não só sobre os verbos regulares, mas também sobre os verbos irregulares, e atividades de listening e speaking, apenas uma atividade de speaking contribuiu para este trabalho, quando a professora perguntou aos alunos "What did you do on your vacation?". Esta pergunta deu margem para que os alunos não usassem apenas o verbo to be, como o caso da primeira pergunta, mas qualquer outro verbo no passado, sendo eles listados na lousa:

Quadro 1. Coleta da aula

\begin{tabular}{|c|c|c|}
\hline Travel & Study & Play \\
\hline Sleep & Watch & Go out \\
\hline Eat & Kiss & Ride \\
\hline
\end{tabular}

Fonte: Elaboração própria

Após o levantamento dos verbos utilizados pelos alunos quando responderam à pergunta da professora, houve frases reproduzidas, tais como: "I ate a lot"; "I slept and watched tv"; "I watched and played"; "I traveled"; "I rode skate"; "I studied". Não houve, porém, a produção adequada do som do prefixo -ed do verbo regular aqui investigado pelo fato de os alunos não terem conhecimento sobre as variações de pronúncia.

Portanto, obteve-se: 
- Aprendizagem da pronúncia de língua inglesa por falantes do português brasileiro: oralidade e articulação do -ed do simple past

Quadro 2. Verbos e pronúncia

\begin{tabular}{|c|c|c|c|}
\hline $\begin{array}{c}\text { Forma base dos } \\
\text { verbos }\end{array}$ & Past tense & $\begin{array}{l}\text { Pronúncia padrão } \\
\text { (Past tense) }\end{array}$ & Pronúncia dos alunos \\
\hline Travel & Travelled & $/$ trævld/9 & /'trævled3/ \\
\hline Study & Studied & /'st $\Lambda$ did/ & /stod3iced3/ \\
\hline Play & Played & /pleid/ & /pleıঞdz/ \\
\hline Watch & Watched & /wotft/ & /watfæd3/ \\
\hline
\end{tabular}

Fonte: Elaboração própria

Gomes (2009, p. 60), em sua tese, conclui que:

Para a formação do passado e do particípio passado, os verbos regulares possuem três alomorfes: / $\mathrm{t} / \mathrm{/} / \mathrm{d} / \mathrm{e} / \mathrm{Id} /$. A falta de conhecimento das regras fonológicas, segundo Celce-Murcia et al. (2004), pode levar o aluno de inglês a pronunciar toda terminação ED como uma sílaba completa /id/ ou /ed/, característica que pode distrair o ouvinte e atrapalhar a comunicação. As autoras afirmam também que alunos em nível intermediário ou avançado têm grande dificuldade em eliminar essa sílaba adicional e produzir os morfemas apropriados.

Diferentemente do que Celce-Murcia et al. (2004) afirmam, neste trabalho houve uma nova ocorrência na qual os alunos pronunciaram a terminação -ed como /æd3/, o que, de certa forma, era um problema já esperado.

\section{Segunda etapa}

Logo após observarmos as quatro aulas na primeira etapa, foi elaborada uma atividade com uma lista de verbos regulares que os alunos deveriam conjugar no simple past e colocar na coluna correta de acordo com a pronúncia. Antes de a atividade ser entregue a todos os alunos da sala de aula, foi feito um processo de coleta por meio de um gravador de áudio em que os informantes selecionados tiveram que pronunciar reservadamente os verbos listados.

9 As palavras faladas pelos informantes foram transcritas de acordo com os símbolos do alfabeto fonético reproduzido no anexo A, extraído de: SELIGSON, Paul; OXENDEN Clive. English File Student's Book. Oxford: Oxford University Press, 1996. 
Esta etapa foi bastante relevante, pois nela os informantes puderam reproduzir as palavras utilizando seus conhecimentos prévios de pronúncia e, desta forma, verificou-se como os alunos receberam as atividades de input e criou-se um conjunto de dados que servirão à comparação com o output pós-intervenção (terceira etapa).

Portanto, observou-se:

Quadro 3. I Coleta da pronúncia dos informantes

\begin{tabular}{|c|c|c|c|c|}
\hline $\begin{array}{l}\text { Forma base dos } \\
\text { verbos }\end{array}$ & Past tense & $\begin{array}{l}\text { Pronúncia } \\
\text { padrão } \\
\text { (Past tense) }\end{array}$ & $\begin{array}{l}\text { Pronúncia da } \\
\text { Fernanda }\end{array}$ & $\begin{array}{l}\text { Pronúncia do } \\
\text { Antônio }\end{array}$ \\
\hline Add & Added & /ædid/ & /adæd3/ & /'eided3/ \\
\hline Phone & Phoned & /farnd/ & /'foned3/ & /'faunded3/ \\
\hline Rest & Rested & /restid/ & /ristəd3/ & /'risted3/ \\
\hline Call & Called & /ko:ld/ & /kolæd/ & /kaul'ded3/ \\
\hline Visit & Visited & /'visitid/ & /'visitæd3/ & /vis'ted3/ \\
\hline Mix & Mixed & /mikst/ & /'miksæd3/ & /mi'zed3/ \\
\hline Like & Liked & /larkt/ & /'larkæd3/ & /lai'ked3/ \\
\hline Explode & Exploded & /Ik'spləodid/ & /æks'pləudæd3/ & /s'plovdedz/ \\
\hline Watch & Watched & /wntft/ & /watjæd3/ & /wa'tsedz/ \\
\hline Laugh & Laughed & /la:ft/ & /laugæd3/ & /lau'ged3/ \\
\hline Believe & Believed & /br'li:vd/ & /bi'lived3/ & /bilíved3/ \\
\hline Want & Wanted & /wpntid/ & /wantæd3/ & /wan'teid3/ \\
\hline Stop & Stopped & /stppt/ & /s'tppæd3/ & /sta'pæd3/ \\
\hline Need & Needed & /ni:did/ & /'nidæd3/ & /ni'dæd3/ \\
\hline Kiss & Kissed & /kist/ & /'kisæd3/ & /kı'zæd3/ \\
\hline Live & Lived & /Irvd/ & /'laivæd3/ & /'laivd/ \\
\hline Finish & Finished & $/$ finift/ & /'finIfæd3/ & /finı'fæd3/ \\
\hline
\end{tabular}

Fonte: Elaboração própria

Percebe-se que os verbos por ambos os informantes foram pronunciados diferentemente da pronúncia padrão. Tendo em vista que esta pesquisa tem como objetivo analisar a pronúncia do - ed dos verbos no passado simples do inglês, nota-se que os informantes fizeram a pronúncia semelhante em quase todos os verbos, variando entre /æd3/ e /ed3/, o que, de acordo com observação em estágios e experiência de sala de aula, é um erro comum entre os aprendizes brasileiros da língua inglesa, que procuramos evidenciar neste trabalho. 
- Aprendizagem da pronúncia de língua inglesa por falantes do português brasileiro: oralidade e articulação do -ed do simple past

SegundoSchütz e Kanomata (2008, p.1), há uma explicação para esta problemática:

Estudantes de idiomas que acreditam ouvir na língua estrangeira sons quase idênticos aos da língua materna (apesar de talvez reconhecerem pequenas diferenças fonéticas entre as duas línguas) irão basear sua pronúncia ao longo do processo de aprendizado num modelo acústico resultante de pares de sons semelhantes das duas línguas, em vez de baseá-la no modelo acústico específico da língua estrangeira, assim como ocorre no aprendizado da língua materna.

E acrescentam,

[...] que os ouvidos do aprendiz não irão reconhecer os sons da língua estrangeira como eles realmente são. Este é um forte argumento em favor de um estudo fonológico detalhado dos contrastes entre a língua materna e a língua que se busca aprender - condição imprescindível para um bom professor de inglês. Uma apresentação detalhada dos dois sistemas fonológicos ajudará o aluno a tomar consciência cedo de que os sons de um e outro idioma não são exatamente iguais, e que essas diferenças podem ser relevantes no significado, afetando o entendimento. (SCHÜTZ, 2017, p. 1).

\section{Terceira etapa}

Após a coleta das pronúncias dos informantes selecionados na segunda etapa, foi planejada uma intervenção. Quando se pensa em fazer uma proposta de intervenção, além de buscar soluções para o problema apresentado, deve-se elaborar um detalhamento sobre os meios necessários para realizar a proposta. Para isso, são necessárias soluções que apresentem uma conexão com os argumentos desenvolvidos ao longo do trabalho.

O objetivo da intervenção foi mostrar aos alunos a importância do conhecimento dos sons do sistema da LI (fonologia) de modo que isso traga melhoras a suas pronúncias.

Após a primeira coleta dos informantes, foram apresentados o alfabeto fonético da LI e uma folha explicando e especificando as regras e as variações da pronúncia do -ed em todos os casos apresentados. Essas atividades são atividades de input, pois envolvem as habilidades de compreensão oral e escrita. Em seguida, uma atividade em que os alunos deveriam conjugar todos os verbos no simple past e depois colocar na coluna que correspondesse à pronúncia padrão foi desenvolvida, evitando consultar o material 
contendo as regras a fim de se avaliar a capacidade de absorção. Essa última atividade é uma atividade de output, que envolve as habilidades de produção oral e escrita.

A primeira coleta se fez necessária antes da intervenção para que permitisse ao pesquisador elaborar uma proposta de ação adequada que atendesse as defasagens de pronúncia. No momento da intervenção, foram expostos e explicados o alfabeto fonético e as regras a todos os alunos e solicitou-se que tentassem repetir a pronúncia dos verbos. Após a explicação, foi entregue a atividade a todos e solicitou-se que conjugassem os verbos no simple past, colocando-os na coluna do alomorfe correto: / $/$, /d/ ou /id/. Depois, realizou-se a correção dessa atividade e determinou-se que os alunos repetiriam a pronúncia dos verbos, após ouvirem a pronúncia do professor.

Ao deixar os alunos realizarem esta atividade, foi possível observar seu envolvimento e interesse, pois não apenas conjugavam e colocavam os verbos nas colunas, como também tentavam pronunciar em voz alta cada verbo com as três terminações com objetivo de identificar a pronúncia mais adequada e colocá-la na coluna correta. Mesmo assim, durante a correção, muitos erraram as colunas, pois houve influência do fonema da língua materna.

Por fim, houve o tempo de uma semana para que os alunos informantes estudassem para fazer a segunda e última coleta para análise do trabalho (quarta etapa).

\section{Quarta etapa}

Para a quarta etapa, onde ocorre a segunda coleta dos informantes, foi estabelecida uma semana para que os alunos/informantes pudessem estudar melhor e memorizar as regras das variações de pronúncia. Portanto, realizou-se uma nova coleta por meio de gravador de voz da mesma lista de verbos da primeira coleta.

Eis os resultados obtidos: 
- Aprendizagem da pronúncia de língua inglesa por falantes do português brasileiro: oralidade e articulação do -ed do simple past

Quadro 4. II Coleta da pronúncia dos informantes

\begin{tabular}{|c|c|c|c|c|}
\hline $\begin{array}{l}\text { Forma base dos } \\
\text { verbos }\end{array}$ & Past tense & $\begin{array}{l}\text { Pronúncia padrão } \\
\text { (Past tense) }\end{array}$ & $\begin{array}{l}\text { Pronúncia da } \\
\text { Fernanda }\end{array}$ & $\begin{array}{l}\text { Pronúncia do } \\
\text { Antônio }\end{array}$ \\
\hline Add & Added & /ædıd/ & /'eded/ & /'eidid/ \\
\hline Phone & Phoned & /faond/ & /faond/ & /'foned/ \\
\hline Rest & Rested & /r'estid/ & /r'estid/ & /r'estid/ \\
\hline Call & Called & $/ \mathrm{ko}: \mathrm{ld} /$ & /ko:ld/ & /ko:Ird/ \\
\hline Visit & Visited & /'visitıd/ & /'visitd/ & /'vi:zit/ \\
\hline Mix & Mixed & /mikst/ & /mrkst/ & /mrkst/ \\
\hline Like & Liked & /larkt/ & /larkt/ & /larkt/ \\
\hline Explode & Exploded & /Ik'sploudid/ & /æk'spləudd/ & /'splovdd/ \\
\hline Watch & Watched & /wptst/ & /wptft/ & /wots/ \\
\hline Laugh & Laughed & /la:ft/ & /la:ft/ & /laudi/ \\
\hline Believe & Believed & /br'li:vd/ & /br'li:vd/ & /bi'li:vd/ \\
\hline Want & Wanted & /wpntid/ & /wantd/ & /wantt/ \\
\hline Stop & Stopped & /stppt/ & /s'toped/ & /'spləudi/ \\
\hline Need & Needed & /ni:did/ & /'ni:ded/ & /nidd/ \\
\hline Kiss & Kissed & /kIst/ & /kist/ & /kIst/ \\
\hline Live & Lived & /Irvd/ & /Irvd/ & /larvd/ \\
\hline Finish & Finished & /'finift/ & /'finift/ & /'finift/ \\
\hline
\end{tabular}

Fonte: Elaboração própria

Na quarta e última etapa do trabalho pôde-se perceber, por meio da coleta, que mesmo contando com pouco tempo de estudo, os informantes apresentaram cerca de $70 \%$ de aproveitamento. Consideramos aqui como resultado positivo não somente as pronúncias realizadas exatamente conforme o padrão, mas também aquelas que se aproximaram dele, distanciando-se da forma equivocada anterior a ponto de não mais gerarem incompreensão ou confusão de sentido. É válido destacar que, embora a pesquisa trate exclusivamente da pronúncia do -ed do Simple Past, consideramos nesse resultado a pronúncia da palavra toda, pois houve evolução não só na pronúncia do -ed como também nos outros morfemas que compõem o vocábulo, e seria injusto desconsiderá-la. Estes resultados ainda não são os desejados, entretanto, acreditamos que com mais tempo e dedicação (do aluno) e insistência (do professor), o estudante tenha a possibilidade de atingir $100 \%$ dos resultados almejados. 
De 17 verbos no total, o informante 1 conseguiu pronunciar 11 corretamente e 6 parcialmente corretos, distanciando-se da pronúncia anterior e aproximando-se da pronúncia padrão, apresentando um output de $85 \%$ do que foi ensinado enquanto o informante 2 conseguiu pronunciar 9 corretamente e 5 parcialmente corretos, apresentando um output de $59 \%$.

Além disso, percebeu-se que em alguns verbos no passado os informantes misturaram sons do português com sons do inglês como, por exemplo, os sons das vogais " $\mathrm{e}$ " e " $\mathrm{o}$ " (fechados) do português, que são inexistentes no inglês. Houve, inclusive, a pronúncia bastante diferente da padrão de um dos verbos pelo informante 2. Nesse caso, pode ter havido uma confusão ou desatenção na leitura.

Ao confrontarmos os resultados da Fernanda com os resultados do Antônio, é possível perceber que o desempenho dela foi superior. Talvez o ocorrido encontre explicação em Schütz (2017) que afirmam que, no caso de adolescentes e adultos, no início do aprendizado, quando são expostos de forma prematura à produção escrita, formam a matriz fonológica da língua a partir da imagem acústica disponível em sua língua materna, e desvios de pronúncia tendem a cristalizarem-se ou fossilizarem-se ${ }^{10}$.

\section{Considerações finais}

Neste trabalho, foi possível constatar que os aprendizes brasileiros de LI do CEL da cidade de Assis apresentaram inicialmente dificuldades em pronunciar adequadamente os sons $/ \mathrm{r} d /, / t / \mathrm{e} / d /$ no final dos verbos conjugados no simple past. Na primeira coleta dos informantes (segunda etapa), a ocorrência frequente da pronúncia do -ed foi realizada como /æd3/ e /edz/ em quase todos os casos. Já na terceira etapa, quando foi feita a segunda coleta, é notável positivamente que o som /æd3/, que apareceu na primeira coleta já não aparece mais. Entretanto, ainda há influência dos sons do português, ou seja, embora tenha ocorrido a substituição de /æd3/ e /edz/ por outros sons na segunda coleta, ainda há a interferência de fonemas da língua materna devido ao fato de parecerem mais próximos, dentro da estrutura geral da sua própria língua.

Na etapa de observação, foi possível identificar a dificuldade considerada pelos alunos na aprendizagem da fonética da LI. Pode ser que isso se dê devido ao fato de ser uma língua rica em sons consonantais, em oposição à língua materna, o português brasileiro, bastante vocálica.

10 De acordo com Schütz (2017), fossilização ou cristalização refere-se aos erros e desvios no uso da LE internalizados e difíceis de serem eliminados. É característica de quem estuda línguas, especialmente na infância, sem ter contato com falantes. 
- Aprendizagem da pronúncia de língua inglesa por falantes do português brasileiro: oralidade e articulação do -ed do simple past

Outro ponto que deve ser destacado neste trabalho é a contradição encontrada no curso da LI proposto pelo governo do estado em relação ao material didático. De acordo com a proposta, o curso tem duração de apenas um ano por já ser uma língua oferecida no ensino regular e, portanto, as únicas habilidades privilegiadas seriam produção e compreensão oral, porém o material didático traz muito conteúdo focado na gramática e não em transcrições fonéticas e exercícios que permitam que os alunos tenham acesso à oralidade, além de que o tempo do curso não permite que o trabalho na produção oral seja explorado como deveria.

Por fim, a intervenção em sala de aula possibilitou ao aluno perceber alguns aspectos do input que não sabia ou percebia antes. Neste sentido, acreditamos ter destacado a relevância de abordar não só as variedades de pronúncia do -ed do simple past, mas de apresentar e explorar o alfabeto fonético em sala de aula para que se tenha uma aprendizagem efetiva no que concerne à produção e compreensão oral. Nesta breve pesquisa, acreditamos que, através dos resultados apresentados, houve uma contribuição a fim de promover uma reflexão sobre o ensino da produção oral da LI, auxiliar o aprendizado dos alunos do CEL e expor a dificuldade foco deste trabalho.

\section{REFERÊNCIAS}

BLAND, S. K. Intermediate Grammar: from form to meaning and use. New York: Oxford University Press, 1996.

CALLOU, D.; LEITE, Y. Iniciação à Fonética e à Fonologia. Rio de Janeiro: Zahar, 1995.

CARNEIRO, J. Entendendo os símbolos fonéticos. Rede inglesa. 2012. Disponível em: http://www.redeinglesa.com.br/2012/11/entendendo-ossim bolos-foneticos.html. Acesso em: 17 fev. 2017.

CELCE-MURCIA, M.; BRINTON, D. M.; GOODWIN, J. M. Teaching Pronunciation - A Reference Book for Teachers of English to Speakers of Other Languages. Cambridge: Cambridge University Press, 2004.

ESTADO DE SÃO PAULO, Governo do. Centro de Estudo de Línguas. Disponível em: http://www.educacao.sp.gov.br/centro-estudo-linguas. Acesso em: 25 jun. 2016. 
GOMES, M. L. de C. A produção de palavras do inglês com o morfema -ed por falantes brasileiros: uma visão dinâmica. 2009. Tese (Doutorado) - Faculdade de Filosofia, Ciências e Letras, Universidade Federal do Paraná, Curitiba, 2009. Disponível em: http://dspace.c3sl.ufpr.br/dspace/bitstream/ handle/1884/19779/TESE\%20 VERSAO\%20FINAL\%20POS\%20BANCA.pdf?sequence=1. Acesso em: 23 fev. 2017.

LAFACE, A.; TASHIRO, E. A. Estudos linguísticos e ensino de línguas. São Paulo: Arte e Ciência, 2006.

MAR, G. D. Ensino de língua estrangeira. In: LAFACE, A.; TASHIRO, E. A. Estudos Linguísticos e Ensino de Línguas. São Paulo: Art \& Ciência, 2006. p. 173-192.

Oxford Advanced Learner's Dictionary, 8th edition. Oxford: Oxford University Press, 2010.

ROSA, A. de F.; MAR, G. D. O ensino/aprendizagem em língua estrangeira por meio de Jogos. In: LAFACE, A.; TASHIRO, E. A. Estudos Linguísticos e Ensino de Línguas. São Paulo: Art \& Ciência, 2006. p. 207-226.

SAUSSURE, F. de. Curso de Linguística Geral. São Paulo: Cultrix, 2012.

SELIGSON, P.; OXENDEN, C. English File Student's Book. Oxford: Oxford University Press, 1996.

SOARS, J.; SOARS, L. New headway: intermediate student's book. 4. ed. New York: Oxford University Press, 2009.

SCHÜTZ, R. E. Pronunciation. In: English Made in Brazil - Educational Site. 2017. Disponível em: http://www.sk.com.br/sk-pron.html. Acesso em: 17 fev. 2017.

UR, P. A course in English language teaching. 2. ed. Cambridge: Cambridge University Press, 2012. 
- Aprendizagem da pronúncia de língua inglesa por falantes do português brasileiro: oralidade e articulação do -ed do simple past

COMO CITAR ESTE ARTIGO: CASTILHO, Rafael Alves de; REIS, Marta Aparecida Oliveira Balbino dos. Aprendizagem da pronúncia de língua inglesa por falantes do português brasileiro: oralidade e articulação do -ed do simple past. Revista do GEL, v. 17, n. 2, p. 102-121, 2020. Disponível em: https://revistadogel.gel.org.br/

DOI: http://dx.doi.org/10.21165/gel.v17i2.2443

Submetido em: 28/10/2019 | Aceito em: 08/08/2020. 